\title{
28 Research Square \\ Establishment and Optimization of Molecular \\ Cytogenetic Techniques (45S Rdna-FISH, GISH And \\ Fiber-FISH) In Kiwifruit (Actinidia L.)
}

Yang Zhao

Xinxiang Academy of Agricultural Sciences

Honghong Deng ( $\sim$ denghonghong2010@163.com )

Sichuan Agricultural University https://orcid.org/0000-0002-9036-8006

\section{Yao Chen}

Yunnan Academy of Agricultural Sciences

Jihan Li

Southwest University

Silei Chen

Southwest University

Chunyan Li

Southwest University

Xue Mu

Southwest University

Zhongrong Hu

Yunnan Academy of Agricultural Sciences

Kunming Li

Yunnan Academy of Agricultural Sciences

Weixing Wang

Southwest University

\section{Research Article}

Keywords: Post-hybridization washing temperature, Blocking DNA, Nuclei isolation, Chromosomes, Cytogenetics

Posted Date: March 2nd, 2021

DOI: https://doi.org/10.21203/rs.3.rs-253913/v1

License: (a) (i) This work is licensed under a Creative Commons Attribution 4.0 International License.

Read Full License 


\section{Abstract}

Background: Kiwifruit has long been regarded as 'the king of fruits' for its nutritional importance. However, the molecular cytogenetics of kiwifruit has long been hampered because of the large number of basic chromosome $(x=29)$, the inherent small size and highly similar morphology of metaphase chromosomes. Fluorescence in situ hybridization (FISH) is an indispensable molecular cytogenetic technique widely used in many plant species. Herein, the effects of post-hybridization washing temperature on FISH, blocking DNA concentration on genomic in situ hybridization (GISH), extraction method on nuclei isolation and the incubation time on the DNA fiber quality in kiwifruit were evaluated.

Results: The post-hybridization washing in $2 \times S S C$ solution for $3 \times 5$ min at $37^{\circ} \mathrm{C}$ ensured high stringency and distinct specific FISH signals in kiwifruit somatic chromosomes. The use of $50 \times$ blocking DNA provided an efficient and reliable means of discriminating between chromosomes derived from in the hybrids of $A$. chinensis var. chinensis $(2 n=2 x=58) \times A$. eriantha Benth $(2 n=2 x=58)$, and inferring the participation of parental genitors. The chopping method established in the present study were found to be very suitable for preparation of leaf nuclei in kiwifruit. A high-quality linear DNA fiber was achieved by an incubation of $20 \mathrm{~min}$. The physical size of $45 \mathrm{~S}$ rDNA signals was approximately $35-40 \mu \mathrm{mm}$ revealed by the highly reproducible fiber-FISH procedures established and optimized in this study.

Conclusions: The molecular cytogenetic techniques (45S rDNA-FISH, GISH, and high-resolution fiberFISH) for kiwifruit was for the first time established and optimized in the present study, which is the foundation for the future genomic and evolutionary studies.

\section{Background}

Kiwifruit belonging to the genus Actinidia Lindl. the family Actinidiaceae (Ericales) is one of the most recently domesticated fruit crops [1]. Despite the short history of domestication, kiwifruit has become a commercially important fruit crop throughout the world with an annual production of approximately 4.3 million tonnes in 2018 [2]. At present, China (2.1 million tonnes) is the largest kiwifruit producer, accounting for $50 \%$ of the total, followed by Italy (555K tonnes) and New Zealand (437K tonnes) [2]. As the king of fruits, kiwifruit contains a wide range of nutritional compounds, including sugar, organic acids, dietary fiber, minerals, vitamin E, folic acid, antioxidants and phytonutrients, particularly the exceptionally high content of vitamin $\mathrm{C}[3-5]$. The kiwifruit has developed into an important horticultural cash crop and is not only consumed domestically, but also imports from abroad, constituting a globally traded commodity [5]. The kiwifruit industry has greatly contributed to the global economy by generating over $\$ 10$ billion [6].

Despite substantial study of kiwifruit, little is known about its molecular cytogenetic characteristics. The molecular cytogenetics of Actinidia species have long been hampered because of the large number of basic chromosome $(x=29)$, the inherent small size (between 0.6 and $1.5 \mu \mathrm{m})$ and highly similar morphology of metaphase chromosomes $[7,8]$. Molecular cytogenetics provides an integrated 
representation of molecular biology and cytogenetics, and involves the number, structure, function and behavior of mitotic and meiotic chromosomes, chromosome recombination and transmission, and the physical organization of certain DNA sequences [9]. The advent of fluorescence in situ hybridization (FISH) almost 40 years ago [10] marked the beginning of a new era for molecular cytogenetics [11], and has become an indispensable technique for chromosome identification $[12,13]$ and genome sequencing in plant species [14].

The advancements in availability of genomic resources and degree of resolution, such as genomic in situ hybridization (GISH) and fiber-FISH have widely widened the scope of FISH applications [13], which now range from karyotype characterization to integration of genetic linkage maps with chromosomal maps [12]. Using the total genomic DNA as probe and blocking DNA, GISH is a modification of FISH, and it enables to distinguish chromosomes from different genomes in an intact cell $[13,15]$. As a straightforward technique, GISH has been widely applied to the study of chromosomal evaluation, cytogenetical classification, genomic constitution, polyploidy confirmation, hybrid verification, introgression breeding in horticultural crops [15]. Fiber-FISH allows high-resolution mapping of the repetitive DNA sequences, large and complex genomic loci, and the cloned and organelle DNA molecules on DNA and chromatin fibers $[11,16]$. The application of FISH on extended DNA and chromatin fibers allows the physical mapping of individual genes or other small DNA molecules at a resolution of 1-400 kb [17], with $1 \mathrm{~kb}$ corresponding to ca. $340 \mathrm{~nm}$ on a completely relaxed DNA double helix [18]. The advantage of high resolution of fiber-FISH has thus attracted considerable interest in molecular cytogenetics of different groups of species [11-13].

The majority of cytogenetic studies in the genus Actinidia have been concentrated on chromosome counts [7, 8], ploidy variation determination [19], and chromosome morphology-based karyotype description [20,21]. He et al. [20] reported the diploid $A$. chinensis var. chinensis had 29 pairs of homologous chromosomes with $2 n=2 x=58$. Cytogenetically, the genus Actinidia presented a structured reticulate pattern of diploid $(2 n=2 x=58)$, tetraploid $(2 n=4 x=116)$, hexaploid $(2 n=6 x=174)$, octoploid $(2 n=8 x=232)$ and decaploid $(2 n=2 x=290)$ in a diminishing frequency [7]. The karyotype symmetry (2B), evidenced by the presences of 38 metacentric, 18 submetacentric (2SAT), and 2 telocentric chromosomes, is the characteristic of $A$. chinensis var. chinensis, what makes the individual identification and molecular cytogenetic study challenging [20,21]. Knowledge of molecular cytogenetics can undoubtedly help answer many of the biological questions regarding plant genomics, taxonomy, evolution, phylogeny, genetics and molecular biology [9]. However, to date, molecular cytogenetic studies employing FISH performed in Actinidia L. are very scarce. Consequently, the application of molecular cytogenetic technique in kiwifruit is of great importance.

In the present study, a molecular cytogenetic study was conducted to kiwifruit by means of applying FISH physical mapping of 45S ribosomal DNA (rDNA) sites. In addition, genomic identification of the kiwifruit hybrids was performed by GISH. The high-resolution fiber-FISH technique for kiwifruit was also developed and optimized. The establishment and optimization of $45 \mathrm{~S}$ rDNA-FISH, GISH and fiber-FISH techniques in 
kiwifruit herein would make the detailed FISH-based karyotypes of Actinidia possible and serve as an important molecular cytogenetic basis for future genomic and evolutionary studies.

\section{Results And Discussion}

\section{Effect of post-hybridization washing temperature on fluorescence in situ hybridization in kiwifruit}

After the probe hybridized to the chromosomal DNA, post-hybridization washing is an essential step of FISH protocol to remove the excess unbound or loosely bound probes and separate the non-specific hybrid signals [25]. Post-hybridization washes associated parameters including temperature, salt and detergent solution concentration can be manipulated to remove non-specific interactions [25]. In this study, we tested three different temperatures $\left(35,37\right.$, and $\left.42{ }^{\circ} \mathrm{C}\right)$ of post-hybridization washes in a $2 \times \mathrm{SSC}$ solution (Fig. 1). The salt solution concentration was empirically selected [22].

Stringent post-hybridization washing in $2 \times S S C$ solution for $3 \times 5$ min at $37^{\circ} \mathrm{C}$ ensured the removal of unbound FISH signals and specificity of the detected 45S rDNA signals (Fig. 1a-c). Under low posthybridization washing temperature $\left(35^{\circ} \mathrm{C}\right)$, some non-specific FISH signals, excessive background autofluorescence, and some unscorable green signals diminished the visibility of true FISH signals of $45 \mathrm{~S}$ rDNA (Fig. 1d-f). There existed some generalized background on slides but not at chromosome regions (Fig. 1d-f). The hybridized probes appeared faint and some of them were even washed away under high post-hybridization washing temperature $\left(42^{\circ} \mathrm{C}\right)($ Fig. $1 \mathrm{~g}-\mathrm{h})$.

Optimization of post-hybridization washing temperature is important for achieving optimal hybridization conditions, though several factors affected the efficiency and quality of hybridization [26]. It is recognized that low temperature can lead to inadequate stringency of post-hybridization washing conditions, while high temperature lead to excessive stringency of posti-hybridization washing conditions [27]. Thus, the possible reasons for the non-specific FISH signals (Fig. 1d-f) and the loss of signals (Fig. 1g-h) were assumed to be the insufficient and excessive stringency of post-hybridization conditions, respectively. By evaluating the effects of different post-hybridization washing temperatures on FISH results as presented in Fig. 1, we demonstrated that the post-hybridization washing in $2 \times \mathrm{SSC}$ solution for $3 \times 5 \mathrm{~min}$ at $37^{\circ} \mathrm{C}$ ensured high stringency and distinct specific FISH signals in kiwifruit somatic chromosomes.

\section{Effect of blocking DNA concentration on genomic in situ hybridization in kiwifruit}

GISH is a variation of FISH and has been widely used to distinguish parental chromosomes or chromosome segments $[13,15]$. The utilization of fragmented genomic DNA as probe and non-target genome as blocking DNA in GISH differentiate it from FISH analysis [15]. Higher plant genomes are composed of high proportion of repetitive DNA families and considered highly conserved in plants [28]. Therefore, genome discrimination by GISH often meets considerable complications resulting from the existence of the highly conserved repetitive DNA sequences emerged during the long-term evolution events. GISH works primarily on hybridization of these repetitive DNA sequences [29]. In this case a 
blocking DNA serving as a DNA competitor to avoid the staining of both genomes by the probe DNA is important in hybrids in particular derived from closely related parental genotypes [29].

In the current study, seven different concentrations of blocking DNA were compared to determine what the ratio of probe/blocking DNA are sufficient to inhibit the chromosome labeling of both parental genomes together. The blocking DNA in a concentration 50x higher than that of the labeled maternal genomic DNA probe $(2 \mathrm{ng} / \mu \mathrm{l})$ allows efficient hybridization and discrimination of the parental chromosome sets (Fig. 2a). The use of lower concentrations (less than 50x than that of the labeled paternal DNA probe) of the blocking DNA did not exhibit good results and not enable unambiguous differentiation of the two parental chromosome sets (Fig. 2b). High concentration (over 50 times) of blocking DNA, however, did not generate hybridization signals, probably because of the high similarities between repetitive DNA sequences that are common in the parental genomes [29,30]. The absence of blocking DNA resulted in substantial hybridization sites on whole chromosome sets (Fig. 2c), revealing the need of using blocking DNA. Hence, the use of 50x blocking DNA is an option to GISH protocol for kiwifruit.

Herein, we described an optimal blocking DNA concentration for obtaining reliable and informative GISH results, though the paternal genitors are closely related with morphologically similar and relatively small chromosome sets. In the present study, the GISH technique was first applied to Actinidia L. Our results show that GISH will probably provide an efficient and reliable means of discriminating between chromosomes derived from in the hybrids of $A$. chinensis var. chinensis $(2 n=2 x=58) \times A$. eriantha Benth $(2 n=2 x=58)$, and inferring the participation of parental genitors in the karyotypic constitution of in terspecific hybrids in the future.

\section{An optimal fiber-FISH in physical mapping of 45S rDNA of Actinidia L.}

FISH performed onto extend DNA fibers released from nuclei has provided a valuable high-resolution tool for physical mapping of up to a few kilobases [31-33]. For example, [33] and [23] reported the extended DNA fibers of Arabidopsis thaliana as 3.27 and $2.87 \mathrm{~kb} / \mu \mathrm{m}$, respectively. Nuclei extraction is one of the most critical aspects of a Fiber-FISH protocol, and it cannot be overstressed that finely extended DNA fiber preparations begin with good nuclei extraction [24]. In the present study, two different methods for isolation of nuclei by directly grinding and chopping fresh leaves in isolation buffer were compared to prepare extended DNA fibers (Fig. 3). Fewer nuclei were destroyed using chopping with a blade (Fig. 3a) than grinding in liquid nitrogen (Fig. 3b). Most of the nuclei extracted by the chopping method remained intact (Fig. 3a), while there were more debris presented in the extraction by grinding in liquid nitrogen (Fig. 3b). The concentration of nuclei harvested by the chopping method established in the present study reached approximately $5 \times 10^{6}$ to $5 \times 10^{7}$ nuclei/ml (Fig. 3c). The chopping method established in the present study were found to be very suitable for preparation of leaf nuclei in kiwifruit.

A key element in ensuring fiber-FISH data reproducibility is to obtain well-separated/stretched intact DNA fibers [24]. One critical parameter to achieve the best possible stretching/spreading high-quality DNA 
fibers is the incubation time of nuclei suspension on the glass slide as well as the lysis time [34,35]. To examine the effects of incubation time on the DNA fiber quality, we tested different incubation times of $10,15,20,25$, and 30 min after adding the lysis buffer (Fig. 4).

From our experiment it is evident that $10 \mathrm{~min}$ of the incubation time after adding the lysis buffer proved to be insufficient to obtain extended DNA fibers. Increasing the incubation time to 15 min resulted in, to a certain extent, extended DNA fibers, but some of the nuclei have not been fully lysed (Fig. 4b). As illustrated in Fig. 4c, over 25 min of the incubation time proved to be excessive to obtain extended DNA fiber because the DNA molecules formed a rosary-, like chain of DNA structures with low density. The possible reason for the poor-quality DNA fiber was assumed to be DNA degradation. A high-quality linear DNA molecule was achieved by an incubation of $20 \mathrm{~min}$, and the DNA molecule obtained was straightened and uniformly stretched as presented in Fig. 4d.

In addition, FISH analysis for 45S rDNA on extended DNA fibers in kiwifruit was for the first time performed in this study (Fig. 5). By applying the highly reproducible fiber-FISH procedures in this study, it was estimated the physical size of $45 \mathrm{~S}$ rDNA signals was approximately 35-40 $\mu \mathrm{mm}$ (Fig. 5). As shown in Fig. 5, the 45S rDNA signals appeared as typical beads-on-string pattern of green spots. With the aid of such high-resolution molecular cytogenetic technique established and optimized in the present study, it is possible to accurately chromosome identification, elucidation of evolutionary relationships and delineation of possible chromosomal variations of Actinidia L.

To our knowledge, Actinidia species have large number of basic chromosomes, relatively small chromosomes with highly similar morphology [7, 8]; as a result, unequivocal discrimination of individual chromosomes based on traditional cytogenetic methods is rather challenging. Herein, the establishment and optimization of modern molecular cytogenetic techniques (45S rDNA-FISH, GISH, and high-resolution fiber-FISH) will probably provide the necessary means, coupled with other molecular and bioinformatics approaches such as using repetitive DNA sequences as probes, to accurate chromosome identification (currently underway in our laboratory). The outcome presented here are the foundation for the continued fascinating research in the near future.

\section{Conclusions}

The molecular cytogenetics of Actinidia species have long been hampered because of the large number of basic chromosome $(x=29)$, the inherent small size and highly similar morphology of metaphase chromosomes. In the present study, the effect of post-hybridization washing temperature on FISH in kiwifruit was evaluated. The post-hybridization washing in $2 \times S S C$ solution for $3 \times 5$ min at $37^{\circ} \mathrm{C}$ ensured high stringency and distinct specific FISH signals in kiwifruit somatic chromosomes. GISH technique was first applied to Actinidia and the use of 50x blocking DNA provided an efficient and reliable means of discriminating between chromosomes derived from in the hybrids of $A$. chinensis var. chinensis $(2 \mathrm{n}=2 \mathrm{x}$ $=58) \times A$. eriantha Benth $(2 n=2 x=58)$, and inferring the participation of parental genitors. The chopping method established in the present study were found to be very suitable for preparation of leaf nuclei in 
kiwifruit. A high-quality linear DNA fiber was achieved by an incubation of $20 \mathrm{~min}$. The physical size of 45S rDNA signals was approximately $35-40 \mu \mathrm{mm}$ revealed by the highly reproducible fiber-FISH procedures established and optimized in this study. In conclusion, the molecular cytogenetic techniques (45S rDNA-FISH, GISH, and high-resolution fiber-FISH) for kiwifruit established and optimized here are the foundation for the future genomic and evolutionary studies.

\section{Materials And Methods}

\section{Plant materials and genomic DNA extraction}

Seeds of $A$. chinensis cv. Hongyang were germinated at room temperature on a moist filter paper in petri dishes. Root tips and fresh young leaves of the seedling of $A$. chinensis $\mathrm{cv}$. Hongyang were used as source materials for the mitotic chromosome preparation of FISH and DNA fiber prepariotn of fiber-FISH, respectively. Root tips for the chromosome preparation of GISH were obtained from germinated seeds derived from the cross-hybridization between $A$. chinensis var. chinensis $(2 n=2 x=58) \times A$. eriantha Benth $(2 n=2 x=58)$. Parental genomic DNA was extracted from fresh young leaves using a DNeasy ${ }^{\circledR}$ Plant Mini Kit (Qiagen Inc., Valencia, CA, USA) following the manufacturer's instructions. DNA quality $\left(A_{260 / 280}\right.$ and $A_{260 / 230}$ ratios) and concentration were assessed with a NanoDrop spectrophotometry (ThermoScientific, Waltham, MA, USA). Sterile ultrapure water was ued to prepare solutions in this study.

\section{Chromosome Preparation}

Mitotic chromosomes were obtained following our previously reported protocol [22] with minor modifications. Briefly, the actively growing root tips of approximately $0.5 \mathrm{~cm}$ in length were pretreated with $2 \mathrm{mM}$ 8-hydroxyquinoline (Sigma; dissolving $0.029 \mathrm{~g}$ 8-hydroxyquinoline in $100 \mathrm{ml}$ water) for $2.5 \mathrm{~h}$ in the dark at room temperature (RM), then fixed in a freshly prepared Carnoy's solution, composed of $75 \%$ ethanol and $25 \%$ glacial acetic acid, for a minimum of $3.0 \mathrm{~h}$ at RM and stored at $-20{ }^{\circ} \mathrm{C}$ until further use. Root apices were softened in an enzyme solution consisting of $4.0 \%(\mathrm{w} / \mathrm{v})$ cellulase and $0.4 \%(\mathrm{w} / \mathrm{v})$ pectolyase $\mathrm{Y}-23$ for $100 \mathrm{~min}$ at $37^{\circ} \mathrm{C}$, followed by a $20 \mathrm{~min}$ hypotonic treatment. The root meristems were squashed in a drop of freshly prepared Carnoy's solution on a clean pre-chilled slide and dried on a flame. Slides featuring good-quality metaphase chromosomes were kept at $-20^{\circ} \mathrm{C}$ until further application of molecular cytogenetic techniques.

\section{Probe Labeling}

Dr. Ruiyang Chen (Nankai University, Tianjin, China) is gratefully acknowledged for providing plasmid containing 45S rDNA. Genomic probes were prepared by sonication to 100-500 bp fragments and DNA size was checked using $1 \%$ agarose gel. Fragmented DNA $(100 \mathrm{ng} / \mu \mathrm{l})$ and plasmid harboring the $45 \mathrm{~S}$ rDNA $(100 \mathrm{ng} / \mu \mathrm{l})$ were labeled with digoxigenin-16-dUTP by random-primed labeling method using DIG- 
High Prime DNA Labeling and Detection Starter Kit II (Roche, Mannheim, Germany) following the instruction manual supplied by the manufacturer. Blocking DNA was prepared by autoclaving the total genomic DNA for 5 min which fragmented it into approximately $200 \mathrm{bp}$.

\section{Fluorescence in situ hybridization}

Slide with cytological preparations for $45 \mathrm{~S}$ rDNA-FISH and GISH was firstly dried at $60{ }^{\circ} \mathrm{C}$ in an oven for at a minimum of $3.0 \mathrm{~h}$, treated with $40 \mu \mathrm{l}$ of RNase solution $(100 \mu \mathrm{g} / \mathrm{ml}$ in $2 \times \mathrm{SSC})$ and incubated in a humidified chamber $\left(37^{\circ} \mathrm{C}\right)$ for $1.0 \mathrm{~h}$, followed by three times wash in $2 \times \mathrm{SSC}$ at RT for $5 \mathrm{~min}$ each. The slide was then treated with $0.01 \%(\mathrm{w} / \mathrm{v})$ pepsin (Sigma) for $10 \mathrm{~min}$ at $37^{\circ} \mathrm{C}$, and washed twice in $1 \times \mathrm{PBS}$ at RT for 5 min each. Following this, the slide was immersed in 1\% formaldehyde (Sigma) at RT for 5 min, and then rinsed three times in $2 \times \mathrm{SSC}$ at RT for 3 min each. The wash steps above and below were performed with a shaker platform set at $150 \mathrm{rpm}$.

The hybridization mix of FISH (20 $\mu$ l for one slide), consisting of $10 \mu$ l deionized formamide (Sigma), $4 \mu$ l $50 \%$ dextran sulfate (Sigma), $2 \mu \mathrm{l} 20 \times \mathrm{SSC}(\mathrm{pH} 7.0), 1 \mu \mathrm{l} 10 \mathrm{mg} / \mathrm{ml}$ sperm ssDNA, $2 \mathrm{ng} / \mu \mathrm{l}$ probe DNA, and $\mathrm{ddH}_{2} \mathrm{O}$, were thoroughly mixed, denatured at $100{ }^{\circ} \mathrm{C}$ for $10 \mathrm{~min}$ in a thermocycler (Eppendorf

Mastercycler) and immediately cooled it on ice for at least $10 \mathrm{~min}$. The chromosomal DNA was denatured by putting slides in $70 \%\left(\mathrm{v} / \mathrm{v}\right.$ ) formamide (in $2 \times \mathrm{SSC}$ ) solution at $72{ }^{\circ} \mathrm{C}$ for $2 \mathrm{~min}$. The slides were then dehydrated in a series of $70 \%, 95 \%$ and $100 \%$ ethanol at $-20{ }^{\circ} \mathrm{C}$ for $5 \mathrm{~min}$ in each solution, followed by air dry. Probe hybridization, signal detection and chromosome photo-documentation were in the same manner as previously reported [22]. Post-hybridization washes are essential to a FISH protocol to remove the non-specific hybrid signals. Three temperatures (i. e. 35,37 , and $42^{\circ} \mathrm{C}$ ) of post-hybridization washes were compared.

\section{Genomic in situ hybridization}

GISH protocol was in accordance with the FISH protocol above with slight modifications in the hybridization mixture, where the probe DNA was replaced by the equal concentration $(2 \mathrm{ng} / \mu \mathrm{l})$ of fragmented genomic DNA of paternal genitor, and the fragmented maternal DNA was added as the blocking DNA. Seven different concentrations of blocking DNA including 0 (0x), 40 (20x), 60 (30x), 80 (40x), 100 (50x), $120(60 x)$ and $140(70 x) \mathrm{ng} / \mu$ l were applied.

\section{Interphase Nuclei Extraction}

Two different leaf nuclei extraction methods by grinding and chopping followed the methods of [23] and [24], respectively, with some modifications. Two grams of fresh leaf tissue were pooled together and ground to a fine powder in liquid nitrogen. Then, $80 \mathrm{mg}$ powder were transferred to a clean 2-ml tube with $2 \mathrm{ml}$ of precooled nuclei isolation buffer containing $10 \mathrm{mM} \mathrm{MgSO}_{4}, 5 \mathrm{mM} \mathrm{KCl}, 0.5 \mathrm{mM} \mathrm{HEPES}, 1 \mathrm{mg} / \mathrm{ml}$ DTT, and $0.25 \%(\mathrm{v} / \mathrm{v})$ Trition X-100. The samples were then gently shaken on ice for a homogenized stage. The resulting suspension were filtered sequentially via 60 and $30-\mu \mathrm{m}$ mesh nylon membranes, 
while on an ice-cold metal block. The filtrate was centrifuged at $2000 \times g$ for $2 \min$ at $4{ }^{\circ} \mathrm{C}$. The supernatant was removed and the nuclei pellet was suspended in two different volumes (30 and $60 \mu \mathrm{l})$ of nuclei store solution containing $10 \mathrm{mM} \mathrm{MgSO}_{4}, 5 \mathrm{mM} \mathrm{KCl}, 0.5 \mathrm{mM} \mathrm{HEPES}$, and $1 \mathrm{mg} / \mathrm{ml}$ DTT. The concentration of nuclei was determined by staining nuclei with 2-(4-amidinophenyl)-1H-indole-6carboxamidine (DAPI) $(1 \mu \mathrm{g} / \mathrm{ml}$ in $1 \times$ PBS $)$.

Instead of grinding leaves, fresh young leaf samples $(80 \mathrm{mg})$ were finely chopped with a clean razor blade in a total of $2 \mathrm{ml}$ cold nuclei isolation buffer in the second methods. The following procedure was in the same manner as described above. The nuclei in storage solution $(10 \mu \mathrm{l})$ was mixed in an equal volume $(10 \mu \mathrm{l})$ of DAPI solution, and analyzed using an Olympus BX61 epifluorescence microscope (Tokyo, Japan) eq uipped with a Sensys CCD camera (Qimaging Retiga ${ }^{\text {TM }}$ SRV Fast 1394, Vancouver, BC, Canada).

\section{Dna Fiber Extension And Fiber-fish}

Extension of DNA fibers followed the method of [23] with some modifications. The nuclei suspension $(1 \mu \mathrm{l})$ was deposited in a line across one end of poly-L-lysine glass slide (Sigma) and left to air dry for approximately $5 \mathrm{~min}$. Then, $30 \mu \mathrm{l}$ of lysis buffer ( $\mathrm{pH} 7.0)$ containing $0.5 \%(\mathrm{w} / \mathrm{v}) \mathrm{SDS}, 5 \mathrm{mM}$ EDTA, and $100 \mathrm{~m}$ M Tris was added on the top of the nuclei and incubated at room temperature for $10,15,20,25$, and $30 \mathrm{~min}$. DNA fibers were then extended by dragging the suspension of lysed nuclei down the slide slowly and smoothly with the edge of an $18 \mathrm{~mm} \times 18 \mathrm{~mm}$ coverslip. The spreading by gravity were not chosen because it can lead to a nonuniform spreading of biers that result in frequent crossing.

Slide was air-dried for approximately $15 \mathrm{~min}$ to a 'sticky' point, neither wet nor overdried. Slide was fix in Carnoy's solution for $2 \mathrm{~min}$, dried at $60^{\circ} \mathrm{C}$ for $45 \mathrm{~min}$ and then can be used immediately for FISH or stored in $4{ }^{\circ} \mathrm{C}$ for 5-7 days. DNA fiber quality was checked by staining with $5 \mu \mathrm{g} / \mathrm{ml} \mathrm{DAPI}$ at RT for $20 \mathrm{~min}$ and briefly rinsing twice in distilled water, followed by air dry. After staining, the effect of incubation time on the DNA fiber quality was observed under epifluorescence microscope. The fiber-FISH procedures are the same as those in regular FISH protocol above.

\section{Declarations}

\section{Acknowledgements}

Dr. Ruiyang Chen (Nankai University, Tianjin, China) is gratefully acknowledged for providing plasmid containing 45S rDNA.

\section{Authors' contribution}

WW and HD conceived and planned the experiment. YZ, HD, and YC performed the whole experiment. JL and SC participated in and performed the 45S rDNA-FISH experiment. CL and XM participated in and 
performed the GISH experiment. ZH and KL participated in and performed the fiber-FISH experiment. HD wrote and revised the manuscript. All authors read and approved the final manuscript.

\section{Funding}

This work was financially supported by the Fundamental Research Funds for the Central Universities (XDJK2018B038 and XDJK2020C076).

\section{Availability of data and materials}

All data generated or analysed during this study are included in this published article.

\section{Ethics approval and consent to participate}

Not applicable

\section{Consent for publication}

Not applicable

\section{Competing interests}

The authors declare that they have no competing interests.

\section{References}

1. Ferguson AR. Botanical description. In: Testolin R, Huang H, Ferguson AR, editors. Kiwifruit genome, Compend plant genomes. Switzerland: Springer; 2016. p. 1-14.

2. Research and Markets. Kiwi fruits market report 2020: Industry value \& volume, trends, production \& consumption, imports \& exports, prices, and key market players through 2007-2025. 2020. https://www.globenewswire.com/news-release/2020/02/05/1980342/0/en/Kiwi-Fruits-MarketReport-2020-Industry-Value-Volume-Trends-Production-Consumption-Imports-Exports-Prices-and-KeyMarket-Players-Through-2007-2025.html. Accessed 21 Jan 2021.

3. Richardson DP, Ansell J, Drummond LN. The nutritional and health attributes of kiwifruit: a review. Eur J Nutr. 2018;57:2659-76

4. Zehra A, Naik HR, Nayik GA, Kour J, Sangeeta, Bobis O, et al. Kiwi. In: Nayik GA, Gull A, editors. Antioxidants in fruits: Properties and Health benefits. Singapore: Spinger; 2020. p. 547-62.

5. Ma T, Sun X, Zhao J, You Y, Lei Y, Gao G, et al. Nutrient compositions and antioxidant capacity of kiwifruit (Actinidia) and their relationship with flesh color and commercial value. Food Chem. 2017;218:294-304.

6. Wu H, Ma T, Kang M, Ai F, Zhang J, Dong G, et al. A high-quality Actinidia chinensis (kiwifruit) genome. Hortic Res. 2019;6:117. 
7. Ferquson AR, Huang H. Cytology, ploidy and ploidy manipulation. In: Testolin R, Huang H, Ferguson AR, editors. Kiwifruit genome, Compend plant genomes. Switzerland: Springer; 2016. p. 55-63.

8. Bass HW, Birchler JA. Plant cytogenetics- Genome sructure and chromosome function. New York: Springer; 2012.

9. Langer-Safer PR, Levine M, Ward DC. Immunological methods for mapping genes on Drosophila polytene chromosomes. Proc Natl Acad Sci U S A. 1982;79:4381-5.

10. Volpi EV, Bridger JM. FISH glossary: An overview of the fluorescence in situ hybridization technique. Biotechniques. 2008;45:385-409.

11. Jiang J. Fluorescence in situ hybridization in plants: recent developments and future applications. Chromosom Res. 2019;27:153-65.

12. Xu SS, Liu Z, Zhang Q, Niu Z, Jan CC, Cai X. Chromosome painting by GISH and multicolor FISH. In: Kianian SF, Kianian PMA, editors. Plant cytogenetics: Methods and protocols, methods in Molecular Biology. New York: Humana Press; 2016. p. 7-21.

13. Stack SM, Royer SM, Shearer LA, Chang SB, Giovannoni JJ, Westfall DH, et al. Role of fluorescence in situ hybridization in sequencing the tomato genome. Cytogenet Genome Res. 2009;124:339-50.

14. Ramzan F, Younis A, Lim KB. Application of genomic in situ hybridization in horticultural science. Int J Genomics. 2017;2017:1-12.

15. Walling JG, Stupar RM, Jiang J. Methods of fluorescence in situ hybridization on extended DNA fibers (fiber-FISH). In: Bass HW, Birchler JA, editors. Plant cytogenetics, plant genetics and genomics: Crops and models. New York: Spinger; 2012. p. 287-95.

16. Ersfeld K. Fiber-FISH: Fluorescence in situ hybridization on stretched DNA. In: Melville SE, editor. Parasite genomics Protocols. Totowa: Humana Press; 2004. p. 395-402.

17. Heiskanen M, Peltonen L, Palotie A. visual mapping by high resolution FISH. Trends Genet. 1996;12:379-82.

18. Kataoka I, Mizugami T, Kim JG, Beppu K, Fukuda T, Sugahara S, et al. Ploidy variation of hardy kiwifruit (Actinidia arguta) resources and geographic distribution in Japan. Sci Hortic (Amsterdam). 2010;124:409-14.

19. He Z, Huang H, Zhong Y. Cytogenetic study of diploid Actinidia chinensis-karyotype, morphology of sex chromosomes at primary differentiation stage and evolutionary significance. Acta Hortic. 2003;610:379-85.

20. He ZC, Li JQ, Cai Q, Wang Q. The cytology of Actinidia, Saurauia and Clematoclethra (Actinidiaceae). Bot J Linn Soc. 2005;147:369-74.

21. Deng H, Xiang S, Guo Q, Jin W, Cai Z, Liang G. Molecular cytogenetic analysis of genome-specific repetitive elements in Citrus clementina Hort. Ex Tan. and its taxonomic implications. BMC Plant Biol. 2019;19:77.

22. Jackson SA, Wang ML, Goodman HM, Jiang J. Application of fiber-FISH in physical mapping of Arabidopsis thaliana. Genome. 1998;41:566-72. 
23. Li L, Yang J, Tong Q, Zhao L, Song Y. A novel approach to prepare extended DNA fibers in plants. Cytom Part A. 2005;63:114-7.

24. Young AP, Jackson DJ, Wyeth RC. A technical review and guide to RNA fluorescence in situ hybridization. PeerJ. 2020;8:1-27.

25. Bogdanovska-Todorovska M, Petrushevska G, Janevska V, Spasevska L, Kostadinova-Kunovska S. Standardization and optimization of fluorescence in situ hybridization (FISH) for HER-2 assessment in breast cancer: A single center experience. Bosn J Basic Med Sci. 2018;18:132-40.

26. Zordan A. Fluorescence in situ hybridization on Formalin-fixed, paraffin-embedded tissue sections. In: Campbell LJ editor. Cancer cytogenetics: Methods and protocols, mehtods in molecular biology. LLC: Springer Sciencne+Business Media; 2011. p. 189-202.

27. Garrido-Ramos M. Satellite DNA: An evolving topic. Genes (Basel). 2017;8:230.

28. Markova M, Vyskot B. New horizons of genomic in situ hybridization. Cytogenet Genome Res. 2009;126:368-75.

29. Marasek A, Hasterok R, Wiejacha K, Orlikowska T. Determination by GISH and FISH of hybrid status in Lilium. Hereditas. 2004;140:1-7.

30. Valarik M, Bartos J, Kovarova P, Kubalakova M, De Jong JH, Dolezel J. High-resolution FISH on super-stretched flow-sorted plant chromosomes. Plant J. 2004;37:940-50.

31. Jiang J, Gill BS. Current status and the future of fluorescence in situ hybridization (FISH) in plant genome research. Genome. 2006;49:1057-68.

32. Fransz PF, Alonso-Blanco C, Liharska TB, Peeters AJM, Zabel P, Jong JH de. High-resoluiton physical mapping in Arabidopsis thaliana and tomato by fluorescence in situ hybridization to extended DNA fibres. Plant J. 1996;9:421-30.

33. Schwab RAV, Niedzwiedz W. Visualization of DNA replication in the vertebrate model system DT40 using the DNA fiber technique. J Vis Exp. 2011;5-9.

34. Nieminuszczy J, Schwab RA, Niedzwiedz W. The DNA fibre technique - tracking helicases at work. Methods. 2016;108:92-8.

\section{Figures}




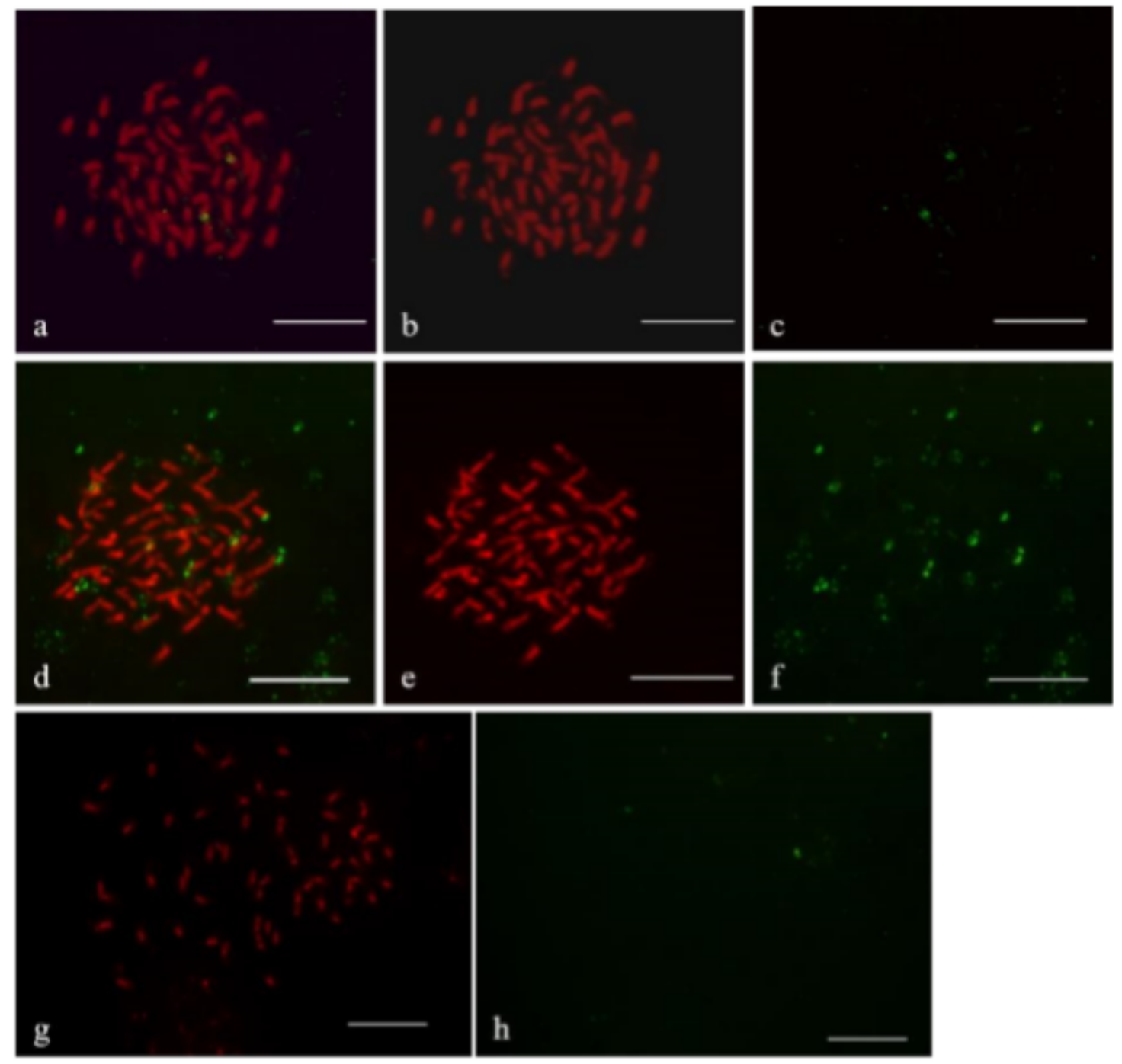

\section{Figure 1}

Observation of post-hybridization washing temperature impact on 45S rDNA-FISH in kiwifruit. The posthybridization washing temperature of 37,35 , and $42^{\circ} \mathrm{C}$ were applied in (a-c), (d-f), and (g, h), respectively. Hybridization sites in (b, $c)$ and $(e, f)$ were digitally separated from the merged images of $(a)$ and $(d)$, respectively. The while scale bar represents $5 \mu \mathrm{m}$.

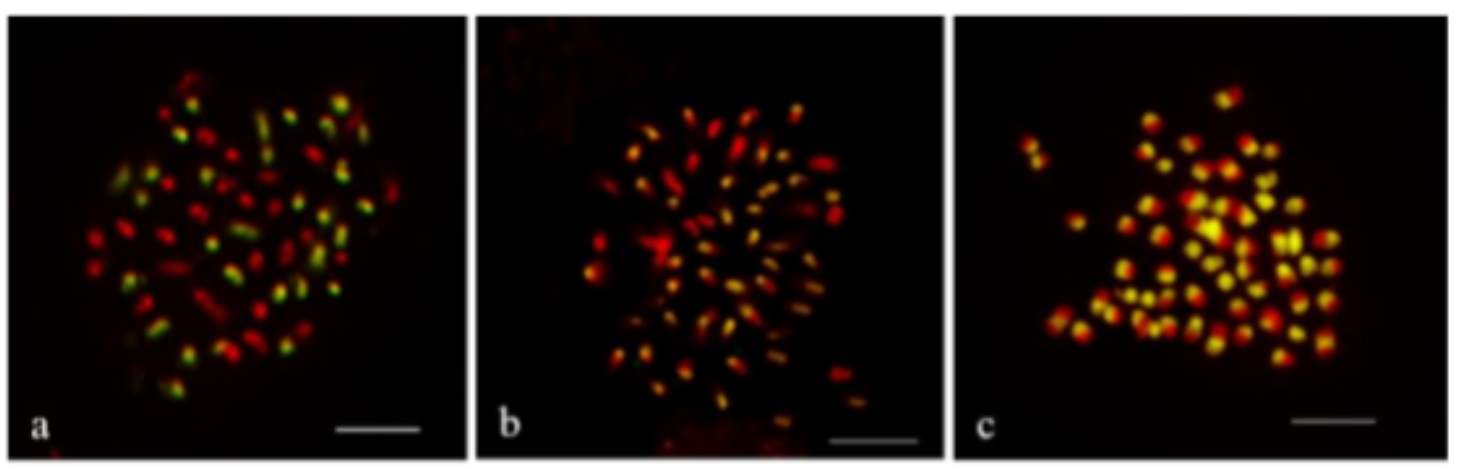

Figure 2 
The effect of blocking DNA concentration on GISH results in kiwifruit. The uses $50 \times(a), 30 \times(b)$ and $0 \times$ (c) more blocking DNA than the probe were compared in this study. The while scale bar represents $5 \mu \mathrm{m}$.
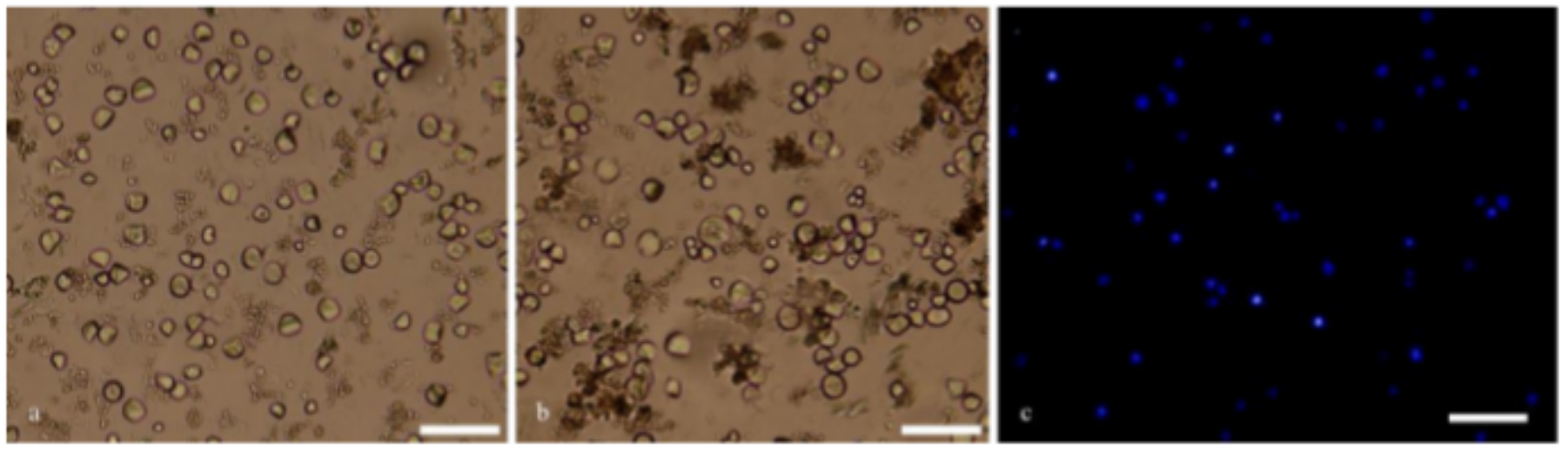

\section{Figure 3}

Comparison of nuclei isolation by chopping and grinding methods in kiwifruit. (a) Nuclei extracted by chopping method, (b) nuclei extracted by grinding method, (c) nuclei extracted by chopping method and stained with DAPI. The while scale bar represents $100 \mu \mathrm{m}$.

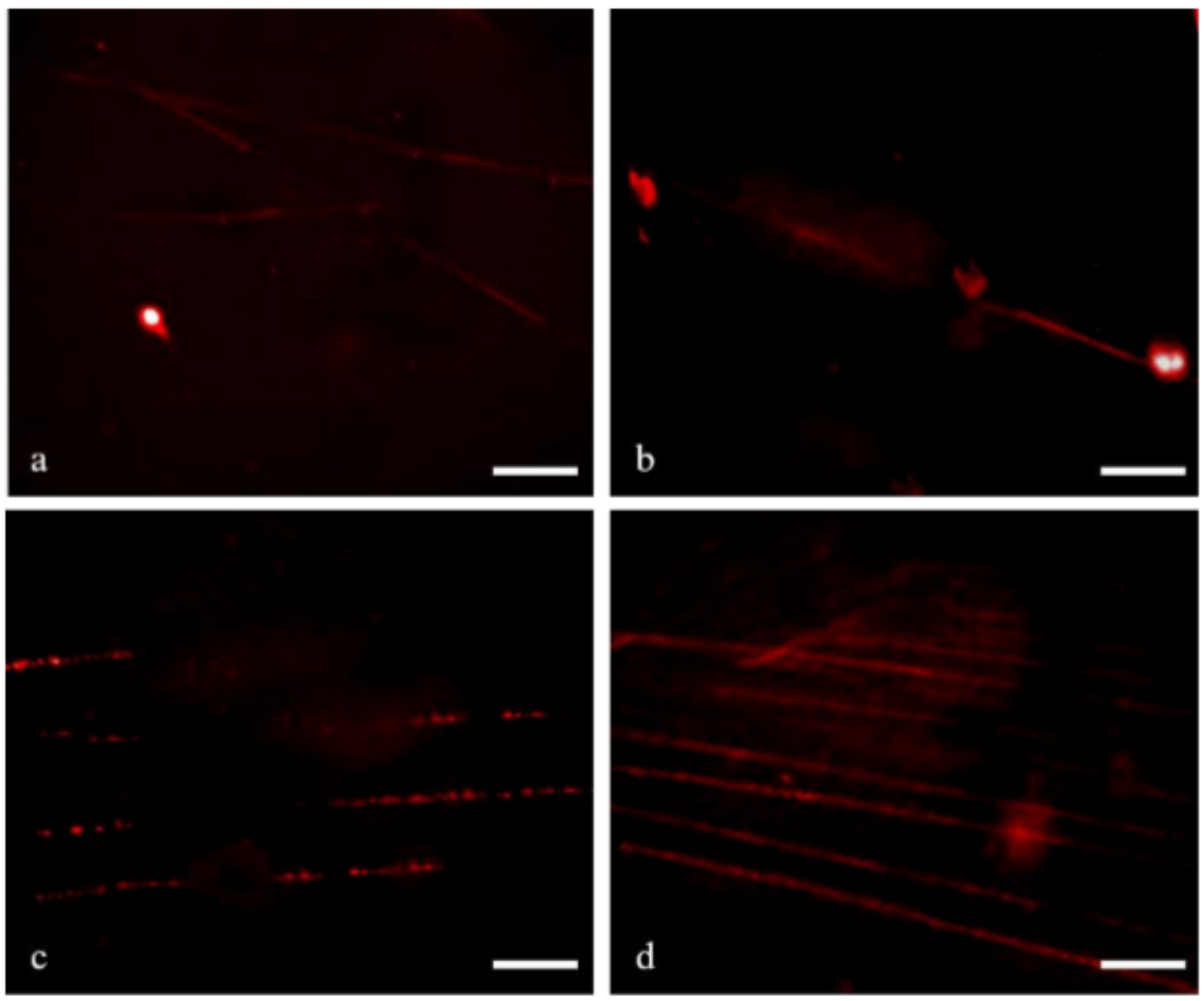




\section{Figure 4}

The effect of incubation time on fiber-FISH results in kiwifruit. The incubation time of 10 (a), 15 (b), 25 (c) and 20 (d) min were compared. The while scale bar represents $5 \mu \mathrm{m}$.

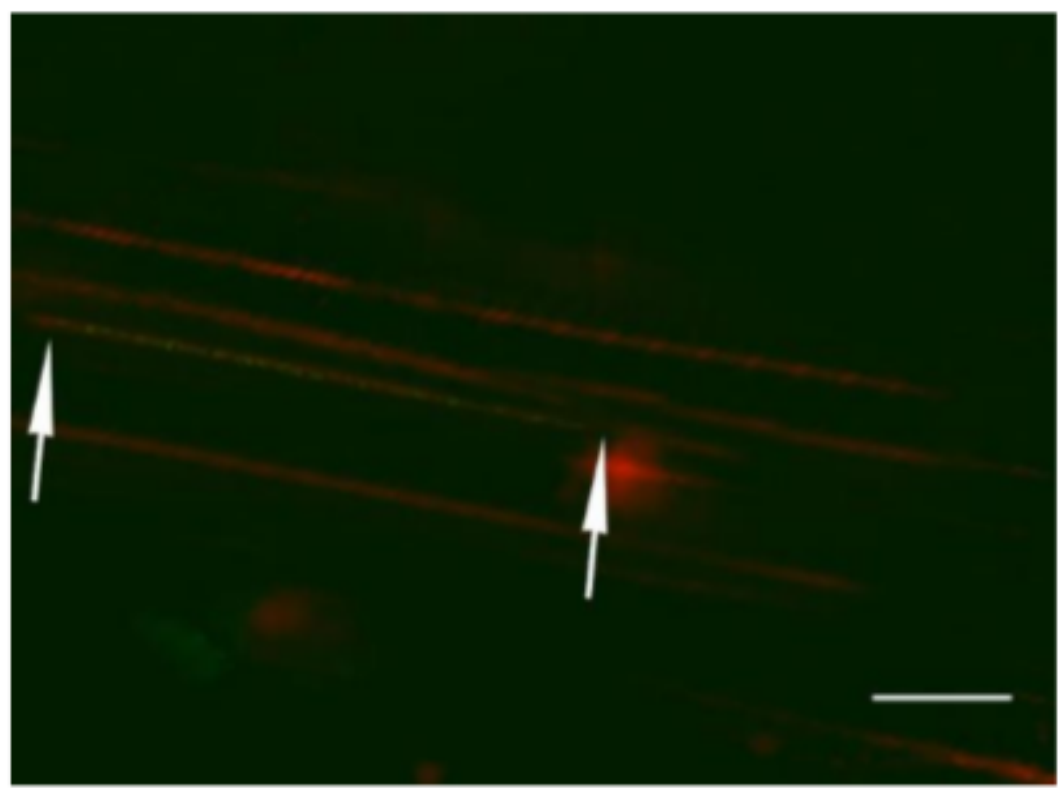

\section{Figure 5}

Localization of 45S rDNA on extended DNA fiber of kiwifruit based on the fiber-FISH protocol established and optimized in this study. The while scale bar represents $10 \mu \mathrm{m}$. 